\title{
Use of RFID Antennas in the Control of Fleet Idleness in an Electric Power Distributor
}

\author{
André Garófalo Chaves ${ }^{1}$, João Paulo Bittencourt ${ }^{2}$, Fellipe Jackson de Queiroga Siqueira ${ }^{3}$, \\ Gustavo Gadelha Chaves ${ }^{3}$, Dalbert Lira Cavalcanti de Lima ${ }^{3}$, Helton Ramalho de Oliveira ${ }^{3}$
}

\author{
${ }^{1}$ Specialist in Financial Management, Audit and Controllership-MBA, João Pessoa, Brazil \\ ${ }^{2}$ Faculty of Economics, Administration and Accounting, USP, São Paulo, Brazil \\ ${ }^{3}$ Logistic Analist at Energisa Power Company, João Pessoa, Brazil \\ Email: *andre.garofalo@gmail.com
}

How to cite this paper: Chaves, A.G., Bittencourt, J.P., de Queiroga Siqueira, F.J., Chaves, G.G., de Lima, D.L.C. and de Oliveira, H.R. (2017) Use of RFID Antennas in the Control of Fleet Idleness in an Electric Power Distributor. Open Access Library Journal, 4: e3922.

https://doi.org/10.4236/oalib.1103922

Received: September 1, 2017

Accepted: October 16, 2017

Published: October 19, 2017

Copyright $\odot 2017$ by authors and Open Access Library Inc.

This work is licensed under the Creative

Commons Attribution International

License (CC BY 4.0).

http://creativecommons.org/licenses/by/4.0/

(c) $)$ EY Open Access

\begin{abstract}
In recent years, the search for better management of the fleet and the reduction of logistic costs has been pursued incessantly by the organizations. One of the alternatives found by Group X was to measure the idleness of its vehicles in order to optimize the use and generate more value for its assets. After perceiving that the vehicles destined to the operating areas were not used every day, it was decided to install RFID antennas in the entrances and exits of the main courtyards to measure the idleness of the fleet. There was an opportunity to reduce the fleet and better allocation of vehicles. But the model has some limitations and faced problems in execution. Although it is a powerful tool, it has not proved ideal for the management of the group's fleet.
\end{abstract}

\section{Subject Areas}

Development Economics, Managerial Economics

\section{Keywords}

Vehicle Monitoring, Vehicle Idling, RFID, Logistics, Transportation

\section{Introduction}

The present work was developed in an Electric Power Distribution Company, identified as Group X, present in several Brazilian states and counts with one of the largest private fleets in Brazil. Due to this magnitude, the Group X has been seeking year after year ways to optimize the use of its vehicles, making them more productive, and trying to lower its cost of operation.

The monitoring of a fleet without the extensive use of technological resources 
is a task that borders the impractical, since the number of occurrences and variables involved is uncontrollable. With this in mind, the Group X created a Planning and Monitoring team ( $\mathrm{P} \& \mathrm{M}$ ) of the fleet, whose mission is to incubate pilot projects that seek performance gains and vehicle management. One of the main problems that the P \& $\mathrm{M}$ team initially detected was the high number of vehicles in the yards during working hours, and to try to reduce this idleness after conducting a study of the main tools on the market at the time, it was proposed to carry out a pilot using RFID technology to control inputs and outputs.

The problem at the time was related to the efficient and effective management of the fleet, since the solutions available in the market were ample, but they also varied in scope of investment. Therefore, the challenge of the P \& M team was to implement a solution that aligned with the specific needs of the company, without investing more than necessary, avoiding erroneous expenses with technology, the inadequate use or even lack of use of the resources acquired, according to the risks presented by [1].

In this way, it was first necessary to analyze the vehicle fleet management profile of the group, which is divided as follows: there is an area controlled by the local fleet coordination called Vehicle Pool, which has shared use, where drivers make a prior request via the system and at the scheduled time and day collect the car with the logistics team. This area is similar to that of an internal car rental company. The other vehicles are for the exclusive use of the departments that need daily use. Such departments request the required amount in the budget period and the vehicles and its expenses are allocated in its cost center respectively.

The idea of using RFID antennas proved to be a potential solution, since the company vehicles stay overnight at headquarters or agency yards. Due to the volume of vehicles being significantly larger in the headquarters of large cities, the project was initiated by large yards. The main gains and expectations of the project were as follows:

- Development of optimization policy for the use of vehicles;

- Promotion of the practice of sharing vehicles between departments;

- Optimization of the use of Vehicles Pool;

- Avoid increase of fleet or even identify opportunities for reduction of the fleet;

- Reduction of taxi use for use of company vehicles;

- Real and online view of idle vehicles inside the yard;

- Reduction of the percentage of rejections of requests due to vehicle unavailability.

The pilot was developed in one of the headquarters of the company, where several tests were carried out by the specialized equipment of the supplier, tests to define better positioning of the antennas, where to install the TAGs in the vehicles, convergence of the information captured with the internal system of the company and the verification of capture during the passage of the vehicle through the gates, which was monitored daily in a manual and systematic way with the objective of measuring at least $99 \%$ accuracy in the readings during the 
movements.

The process of implementing and managing the RFID technology for monitoring idle vehicles in an electric power distributor is studied in this report, as well as its barriers and facilitators. The general objective of the report is to analyze the use of RFID technology in the monitoring of idle vehicles in an electric power distributor.

The methodological path for data collection and analysis was based on the direct participation of one of the authors, the documentation related to the project and the analysis through analytical categories proposed deductively and emerging inductively from the data analyzed.

\section{Theoretical Referential}

The theoretical referential of this report was developed in order to provide an overview of what RFID technology consists of and how it is used in the monitoring of fleets, aspects that support the study.

\subsection{RFID Technology: Operational and Technical Principles}

From the English Radio-Frequency Identification, RFID addresses a method of automatic identification through radio signals, retrieving and storing data remotely in devices called RFID tags. An RFID tag is a transponder, small object that can be placed on a person, animal, equipment, packaging or product, among others. It contains chips and antennas that allow you to respond to radio signals sent by an antenna. RFID is an alternative to bar codes in order to allow the identification of the product from a certain distance, as in toll systems where its use is intense.

According to Hessel et al. [2] deal with the origin of the system by considering that the electronic identification technology was proposed with the objective of identifying targets in the soil, air or sea during the 1930s by the US military. Pessoa et al. [3] explain in relation to such discovery that:

The naval research laboratory, led by Sir Alexander Watson-Watt, developed the Friend-or-Foe Identification System (IFF). Nesse sistema os componentes mais importantes eram um interrogador e um transponder. The base station emitted a radar signal and the transponder, after receiving this signal, reflected it back, causing the radar antenna to receive a stronger return than it would otherwise have (p. 2094).

Sometime later, around the 1970s, the first commercial RFID systems were developed, focusing on the protection of store inventories, known as 1-bit labels, which did not require batteries and were attached to the products on sale and triggered an alarm when near a sensor (reader) usually installed in the doors.

Leite and Silva [4] acknowledge in their research that the United States was a precursor to the use of RFID for commercial purposes, when in the 1970s experiments were carried out to identify vehicles and moving goods, funded by the success of toll systems. 
In the 1980s, frequencies considered Ultra High (UHF) were used, which enabled the use of labels for readings 10 meters away [3]. At the end of the 1990s and in the early 2000s, increased reach, speed and lower prices multiplied the possibilities of using RFID. Therefore, [5] understood that RFID applications have grown at a significant pace, with system deployments in a number of industries such as pharmaceuticals, healthcare, transportation, retail, defense, and logistics. An important aspect of RFID technology is that it can help a wide range of organizations and individuals achieve substantial gains in productivity and efficiency. Radio frequency tags enable the optimization of various business processes by improving, automating or even eliminating existing processes and the emergence of new processes called intelligent processes.

The operation of RFID technology consists of two main components: the transponder ( $\operatorname{tag}$ ), which must be affixed to the object to be identified and the reader or detector, which depends on the adopted technology, able to be a reading or writing device. The reader usually consists of a high-frequency module (which emits and receives), a control unit and the interface for the transponder. Some readers present an additional interface so that they can transmit the received data to another system [6] [7].

Hessel et al. [2] recognize that, in addition to etiquette and reader, the RFID system is equipped with antennas. The reader must connect to a system that can process the data collected through the tag and send radiofrequency signals over the antenna in search of objects to be identified. Thus, the label receives the radiation sent by the antenna and the synchronization between them allows the reception of the data by the reader, which possibly will send to a processing system.

RFID technology makes it possible to identify people, animals, documents, products or vehicles with different management objectives. "In vehicular identification, RFID technology is used in a variety of contexts, such as the control of access to parking lots, the automatic release of tolls, access control in strict areas, vehicle rotation and fleet management and control" [6]. This report focuses on the application of technology in fleet management and control.

\subsection{RFID Applied to Fleet Monitoring}

The improvement of technology, electronics and communication has facilitated the development of solutions that can boost the dynamics of the productive process [6]. In the specific case of fleet management, [8] understood that once a company has a vehicle, it becomes necessary to rational manage this asset. The reasons for this concern are the fact that vehicles are high-cost and moving goods, "creating opportunities for friction, wear due to environmental conditions, damages to the vehicle itself, to other vehicles, to people, such as the driver, the helper or third parties" [8]. In addition, vehicles usually transport people and materials, playing a relevant role in different production systems. Therefore, the company needs to design and implement policies, practices and systems that 
allow the return on investment in its vehicles, to preserve its spare power and ensure its competitiveness.

It has demonstrated why the fields related to fleet management have received increasing economic and technological interest, where markets tend to become increasingly open and competitive. Companies need every day to serve their customers efficiently and effectively, whether through products, processes or services. Zeimpekis et al. [9] (2007) recognized that the challenges of contemporary fleet management go beyond cost and efficiency. Over the last few decades the classical methods of fleet management have addressed the issue of cost efficiency comprehensively, developing routing plans across a broad spectrum of practical problems. "However, the use of an initial plan, although necessary, is insufficient to handle events that may occur during the execution of the plan and significantly affect the performance of the system" [9].

The authors also reported that the use of the fleet to execute requests and calls in real time can generate challenges to the management of vehicles already en route, besides the intrinsic disturbances to urban environments, such as delays in traffic, parking unavailability and breakdowns, or those intrinsic to rural and inaccessible environments, depending on the operation of the organization. The ability to handle these cases satisfactorily is increasingly important for the competitiveness of logistics and operations related with transport. Therefore, [9] propose the dynamic management of fleets, a concept that refers to environments in which information can be dynamically revealed to the decision maker. This information sometimes not be known at the initial planning stage, and/or may change after the construction of the initial routes of the fleet during the execution of the plan. In addition, there are significant cases where there is no routing and the system responds to requests that arrive dynamically. In this context, the use of technology is imperative for the articulation between the resources and the objectives of the company [5].

The rapid growth of information and communication technologies now provides opportunities for obtaining real-time information at lower costs. Ichoua et al. [10] were interested in managing fleet of vehicles in circulation to meet customer requests that are revealed dynamically over time. In such cases, management and operation take place under various operational constraints such as time windows and the limited capacity of the vehicle. In addition to new requests and/or service requests, other types of dynamic events may also occur, such as aspects related to travel dynamics, service cancellations, vehicle breakdowns, etc. Adding to these challenges are labor-related aspects such as qualification and motivation of those involved [8]. Thus, decisions must be made in a changing and challenging environment. The use of RFID may be a technological response to these questions [4].

Pessoa et al. [3] emphasize that the implementation of RFID with the objective of promoting competitive management must meet two requirements: strategic alignment and knowledge management. As for strategic alignment, the authors 
understand that implementing the technology appropriate to the business can become a relevant challenge for the managers of the organizations. In this sense, the authors conceptualize strategic alignment as "the effort and general orientation of the business tactical disciplines in the sense predicted by the strategy adopted by the organization. Thus thinking, an action aligned to the strategy, finds in the latter all the basis for its development and correlation with the other business efforts". The concern with strategic alignment is justified because of the possibility of erroneous spending on technology, misuse or even lack of use [1]. In this way, it matters how the introduction of RFID is aligned with the organization's strategies.

Pessoa et al. [3] still consider that the validation of the application of RFID technology depends on what can be concluded in terms of processes of generation, retention, sharing, strategic monitoring and application of information technology and knowledge in the corporate environment.

The theoretical aspects pointed direct to the analytical categories that underpinned this study. The report of the implementation and management of the RFID technology in the organization studied was carried out according to the following methodological procedures.

\section{Methodology}

The present technical report was elaborated in two stages, starting from the professional experience of the researchers, who elaborated the first version through the use of participant direct observation and the analysis of documents related to the implementation and management of RFID in monitoring of idle vehicle-Final Report of the Yard Monitoring Project [11]; Presentation/System Utilization Training/PMF [12]; Electronic messages of instruction and evaluation of the system [13]; and Suggestion for Vehicle Optimization [14]. The second stage of the report was possible through interaction with the P \& M team, with the objective of analyzing the data and reflecting on the scope of the intended results, the potentialities and the challenges of the use of technology in the case studied. The approach was predominantly qualitative, although the use of reports and secondary data used in process management was relevant to the projection of implementation results.

For the participant observation, the previous experience of the researchers was relevant, among them the first author of the report, who coordinates the P \& M team and has a main activity in the automotive sector and also in the logistics area of a beverage distributor. In addition to the experience of the P \& M team with fleet management, the demands of the areas and the company presented at meetings and recorded in electronic minutes and messages were considered, which was relevant in defining and identifying the problem.

The proposed analytical categories were strategic alignment, knowledge management and, the decrease of vehicle idleness (initial objective of RFID implementation, which emerged from practical experience) [1] [3]. Data analysis was 
guided by the qualitative data analysis model proposed by [15], through data condensation and data visualization, followed by the elaboration and verification of conclusions, which were used iteratively and simultaneously. The data was condensed in first and second level, allowing open and interpretive coding with the support of the families of codes proposed deductively from the theoretical reference of this research and from those that emerged in an inductive way.

\section{Results}

The following section is organized with the intent of presenting the pilot phase, the execution of the project and expansion to other ordinances, as well as the results achieved. The presentation is followed by analysis of the data and drawing conclusions.

\subsection{Pilot Phase}

The pilot project was carried out at one of the locations where approximately 156 vehicles were filled. The performance of the solution was monitored for 30 days, during which it was checked whether the antennas correctly captured all vehicles with the RFID tag as they traveled through the gates.

The illustration shown in Figure 1 outlines the basic solution architecture, i.e. the timing of the capture of RFID tags by the antennas when moving through the gates.

The supplier carried out a site survey prior to the start of the pilot and indicated through a report the appropriate location for the installation of the antennas, the ideal positioning for the application of the tags in the vehicles, the specifications of the infrastructure to be carried out, As well as information regarding the RFID process.

The positioning of the antennas after the realization of the infrastructure performed in the headquarters and the RFID tags positioned on the windshield of vehicles are shown in Figure 2 and Figure 3, respectively.

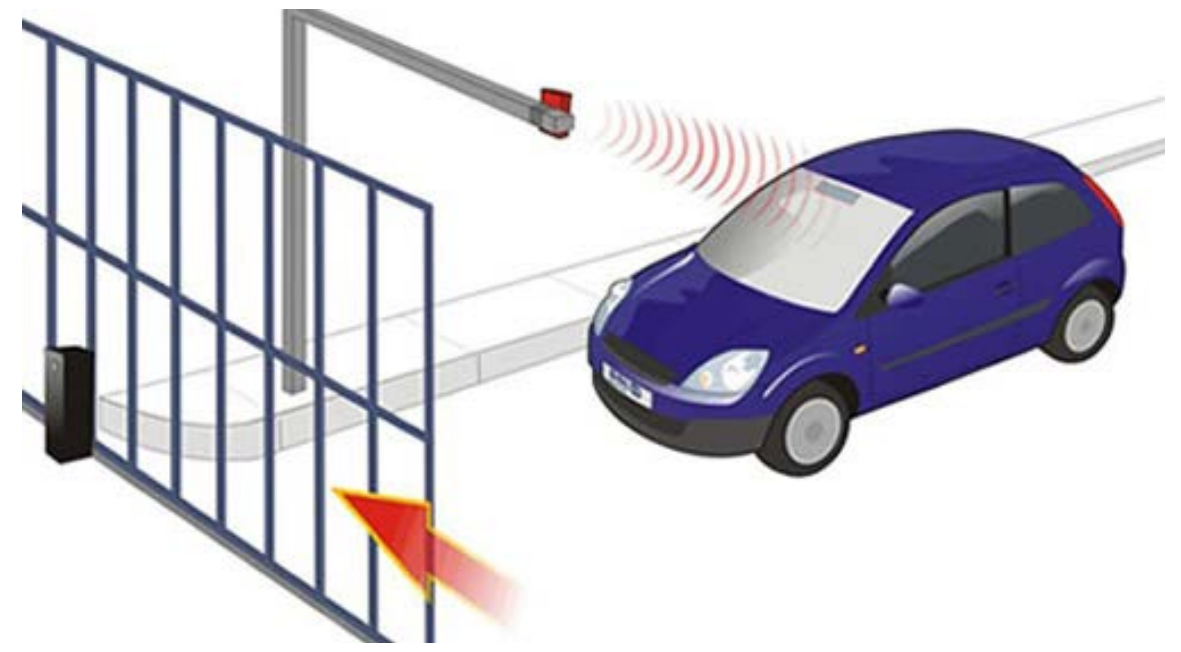

Figure 1. Basic operating architecture of the RFID solution. Source: [11]. 


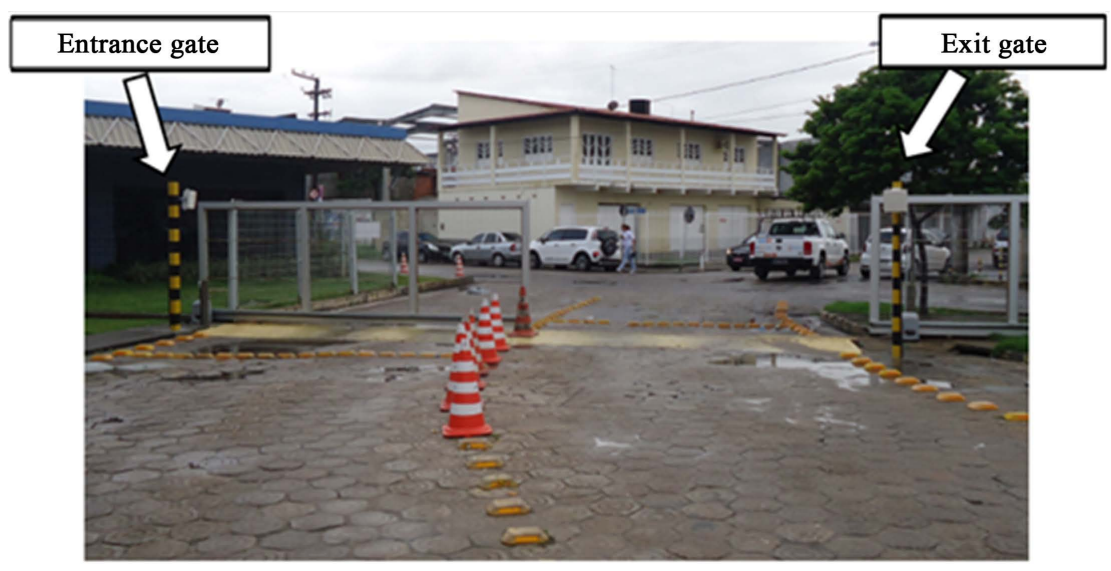

Figure 2. Position of the RFID antennas implanted from the headquarters where the pilot project occurred. Source: [11] [12].

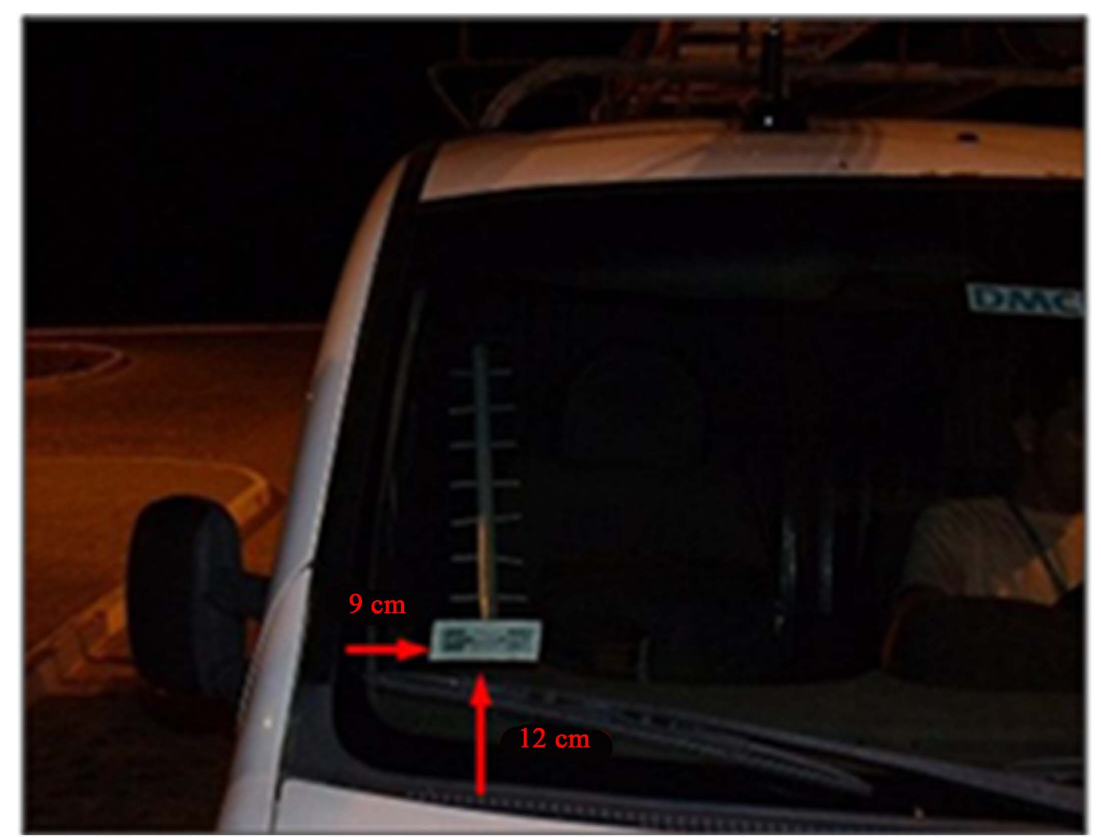

Figure 3. RFID TAG positioned on the vehicle windshield. Source: [11] [12].

After the installation, the assertiveness index of the entrance and exit registry of the yard was measured. Some mishaps at the beginning of the pilot made it difficult for the supplier's system to achieve $99 \%$ of vehicle catches. Software adjustments were necessary to succeed in the assertiveness of the solution.

It should be noted that each parking lot has its peculiarities, so the verification of the assertiveness was performed daily, comparing the records in the internal systems with the records made manually by a professional in the concierge. Assertiveness is only considered accepted after reaching 99\% and staying for 2 weeks.

\subsection{Execution of the Project-Expansion for Other Ordinances}

After accepting the pilot, the supplier made the technical visit to the 5 other 
parking lots and issued their respective Site Survey reports with the location of the antennas at the entrance and exit gates, as well as specifying the need for infrastructure.

In addition to the reports was presented the formal financial proposal of the project. The total cost was estimated at $\mathrm{R} \$ 286$ thousand, of which $65 \%$ (or $\mathrm{R} \$ 185$ thousand) allocated as CAPEX (capital expenditure or investment in capital goods, index that indicates the amount of money spent on the purchase of capital goods of a particular company) and 35\% (or R $\$ 101$ thousand) as OPEX (Operational Expenditure). Figure 4 shows the financial progress of the project month by month.

The financial advance was finalized $\mathrm{R} \$ 10$ thousand less than foreseen in the project (Figure 4). This economy was due to the reuse of computer equipment (UPS, monitor, CPUs, etc.). Parallel to the achievements of the infrastructure preparation activities, therefore, the equipment acquisitions (antennas, readings, computers) and inputs (RFID tags) occurred. Once installed and tested, the P \& $M$ team began to gauge the data and treat them to obtain the expected results.

Due to the integration that the supplier was able to carry out with the company's own system, the Transportation Coordination started to do a real monitoring through the Yard Monitoring Panel, created to act in the management of the entrance and exit of the vehicles against the dates and times of the Pool's vehicle requests. This routine aims to combat the indiscipline and/or lack of care of some users, because there are requests that are made, but the vehicles are not used. In addition, they also promote awareness of using the department's own vehicles before requesting vehicles in the Pool.

In addition to the Monitoring Panel feature, the System query menu has three additional analytical features for monitoring the yard, namely:

- Idle rate per vehicle: the consultation provides Area Managers with the idle rate of their vehicles providing optimization of the use of their vehicles among their teams, sub-department or even another department;

- Check-in and check-out: allows you to check the whole history of the movements of the vehicles;

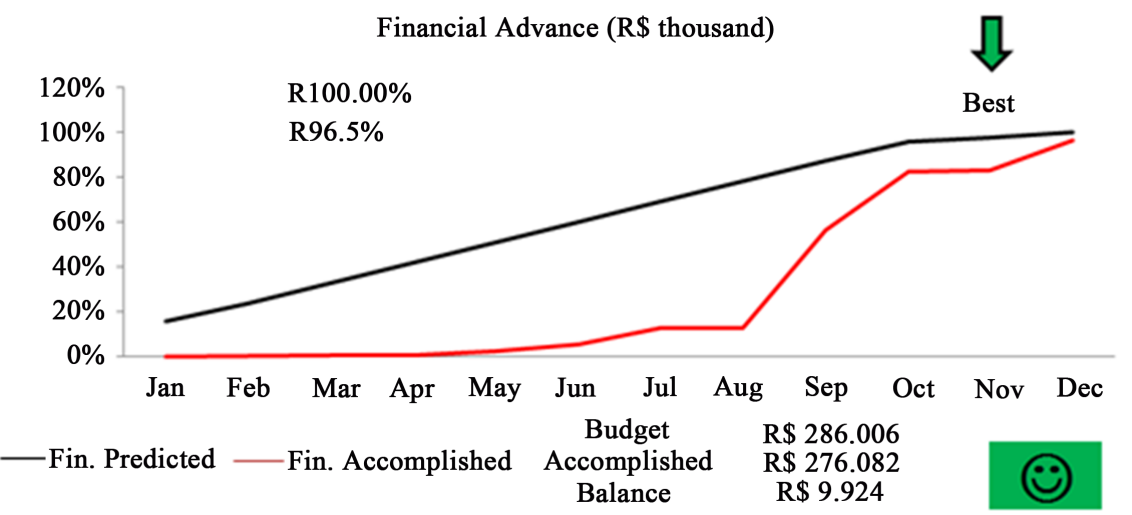

Figure 4. Monthly financial advance of the project. Source: [11]. 
- Vehicle in the yard by date and time: displays the history of vehicles that were inside the yard at a specified date and time period.

It is also possible, using information from analytical resources, to generate synthetic, analytical, and less widely used vehicle rankings reports in each department. These reports are presented monthly to the managers, coordinators and supervisors of the areas in order to promote better utilization, reallocation between departments or even the alienation of vehicles.

At the end of each month, the data are extracted from the vendor's storage system and processed for the purpose of analyzing the administrative hours from 07:30 am to 17:30 pm. Thus, the information was measured and criticized by the managers of each idle vehicle.

Next, you can check in Figure 5, the analyzes of one of the seats, released monthly from the number of vehicles available in that yard (Blue line) and the number of idle vehicles throughout the day, each day (represented by the orange bars).

In addition to this analysis, it was also possible to carry out the dissemination and calculation of the ranking of the idlest vehicles of the month, which also led to the construction of a semiannual document called Vehicle Optimization Suggestion, which suggests relocations of vehicles by department or for the Pool. Suggestions related to the reduction of the fleet are occasionally made, due to the possibility of supplying the need for that vehicle with idle vehicles in the Pool. The following is an example of ranking by department, in Figure 6.

The application of RFID technology has provided a set of actions aimed at reducing the idleness of the Group $\mathrm{X}$ vehicle fleet. The results achieved are analyzed below.

\subsection{Results Achieved}

The implementation of this project has brought satisfactory results to the group. The monitoring of the vehicles in the yards allows the logistics to optimize the management of the fleet. Based on the information generated by the antennas installed in the ordinances, it is possible to better manage the vehicles of the Pool, avoiding idleness in cases where requests are made, but the vehicles are not

Monitoring of fleet utilization-Headquarters (May/2016)

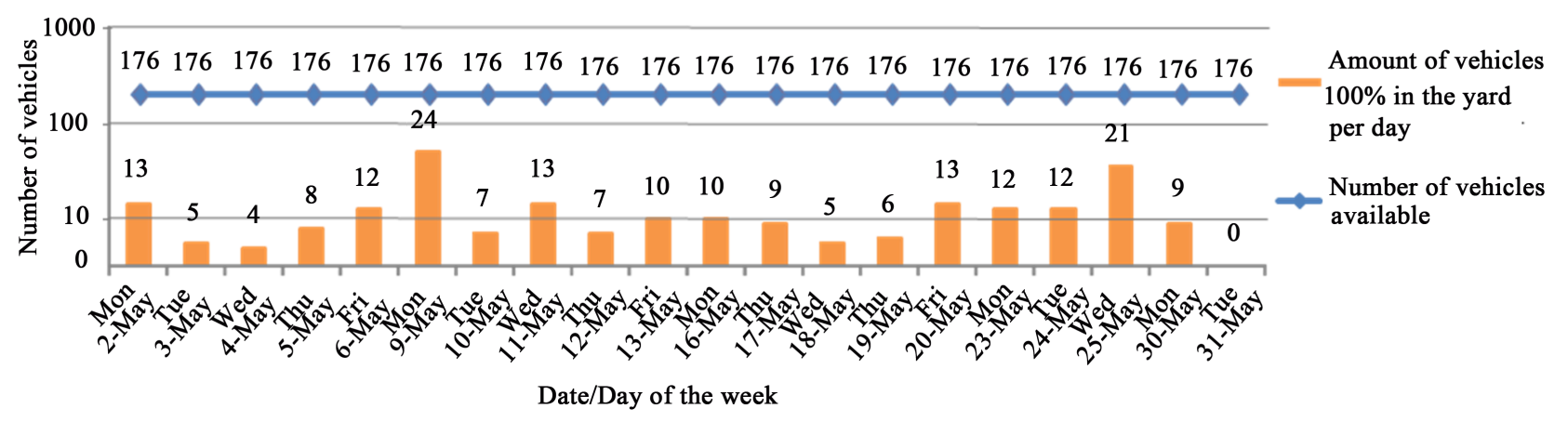

Figura 5. Follow-up of the management of the fleet in the period of May 2016, in one of the headquarters. Source: [11]. 


\begin{tabular}{|c|c|c|c|c|c|c|c|}
\hline \multicolumn{8}{|c|}{ Ranking of the most idle vehicles } \\
\hline Seq. & $\mathrm{N}^{\circ}$ of fleet & Class & Model & Year Fab. & Department & $\%$ of idle days & Amount of days $100 \%$ \\
\hline $1^{\circ}$ & 2112 & $\mathrm{~L}$ & Saveiro 1.6 & 2012 & DMCP & $55 \%$ & 11 \\
\hline $2^{\circ}$ & 6013 & $\mathrm{~L}$ & Saveiro 1.6 & 2013 & DMCP & $45 \%$ & 9 \\
\hline $3^{\circ}$ & 9614 & $\mathrm{~L}$ & Saveiro $1.6 \mathrm{Ml}$ & 2014 & DMCP & $45 \%$ & 9 \\
\hline $4^{\circ}$ & 9014 & $\mathrm{~L}$ & Saveiro $1.6 \mathrm{Ml}$ & 2014 & DMCP & $45 \%$ & 9 \\
\hline $5^{\circ}$ & 9214 & $\mathrm{~L}$ & Saveiro $1.6 \mathrm{Ml}$ & 2014 & DMCP & $35 \%$ & 7 \\
\hline $6^{\circ}$ & 6713 & $\mathrm{~L}$ & Saveiro 1.6 & 2013 & DMCP & $30 \%$ & 6 \\
\hline $7^{\circ}$ & 8814 & $\mathrm{~L}$ & Saveiro $1.6 \mathrm{Ml}$ & 2014 & DMCP & $15 \%$ & 3 \\
\hline $8^{\circ}$ & 6513 & $\mathrm{~L}$ & Saveiro 1.6 & 2013 & DMCP & $15 \%$ & 3 \\
\hline $9^{\circ}$ & 7213 & $\mathrm{~L}$ & Saveiro 1.6 & 2013 & DMCP & $15 \%$ & 3 \\
\hline $10^{\circ}$ & 8514 & $\mathrm{~L}$ & Saveiro $1.6 \mathrm{Ml}$ & 2014 & DMCP & $15 \%$ & 3 \\
\hline $11^{\circ}$ & 7413 & $\mathrm{~L}$ & Saveiro 1.6 & 2013 & DMCP & $10 \%$ & 2 \\
\hline $12^{\circ}$ & 6715 & $\mathrm{~L}$ & Saveiro 1.6 & 2015 & DMCP & $10 \%$ & 2 \\
\hline $13^{\circ}$ & 7113 & $\mathrm{~L}$ & Saveiro 1.6 & 2013 & DMCP & $10 \%$ & 2 \\
\hline $14^{\circ}$ & 7215 & $\mathrm{~L}$ & Saveiro 1.6 & 2015 & DMCP & $10 \%$ & 2 \\
\hline $15^{\circ}$ & 9814 & $\mathrm{~L}$ & Saveiro $1.6 \mathrm{Ml}$ & 2014 & DMCP & $10 \%$ & 2 \\
\hline $16^{\circ}$ & 9914 & $\mathrm{~L}$ & Saveiro $1.6 \mathrm{Ml}$ & 2014 & DMCP & $5 \%$ & 1 \\
\hline $17^{\circ}$ & 6015 & L & Saveiro 1.6 & 2015 & DMCP & $5 \%$ & 1 \\
\hline $18^{\circ}$ & 7013 & $\mathrm{~L}$ & Saveiro 1.6 & 2013 & DMCP & $5 \%$ & 1 \\
\hline $19^{\circ}$ & 7313 & $\mathrm{~L}$ & Saveiro 1.6 & 2013 & DMCP & $5 \%$ & 1 \\
\hline $20^{\circ}$ & 8914 & $\mathrm{~L}$ & Saveiro $1.6 \mathrm{Ml}$ & 2014 & DMCP & $5 \%$ & 1 \\
\hline $21^{\circ}$ & 9015 & L & Saveiro 1.6 & 2015 & DMCP & $5 \%$ & 1 \\
\hline
\end{tabular}

Figure 6. Ranking of the idlest vehicles reported to the departments. Source: [13] [14].

used. The project also allowed for the analysis of fleet reduction, avoiding expansions by relocating vehicles between areas, reducing controllable expenses (OPEX) and investments in fleet (CAPEX).

In the first vehicle relocation suggestion report, the avoided investment was of the order of $\mathrm{R} \$ 789.91700$ (Table 1), only moving vehicles between areas or reducing the fleet. In addition to the tangible gain, the evolution and maturation of the local transport teams is evident due to the acquisition of these new resources, which demonstrates a greater control of the vehicles and the achievement of a new level in the management of available resources. Nevertheless, there is a greater awareness of the managers of other areas in making the best use of their vehicles, improving the percentage of their use, as well as better scheduling of the teams' activities, keeping them in the field, producing, for longer, avoiding to leave the idle vehicles in the courtyards.

Among the results achieved, from the conceptually proposed categories, is the strategic alignment of the implementation and management of technology in Group X. Pessoa et al. [3] emphasize the importance of investments being made in an articulated way to the strategic objectives of the organization and [1] understands the importance of avoiding unnecessary expenses and investments. In this sense, the present report points to an assertive investment and that generated, besides financial gains for the organization, an evolution in the field of information regarding the fleet by the local transport team. 
Table 1. CAPEX investment avoided.

\begin{tabular}{clc}
\hline Yard & \multicolumn{2}{c}{ CAPEX investment avoided } \\
\hline Yard 1 & R\$ & $304,288.00$ \\
Yard 2 & R\$ & $200,549.00$ \\
Yard 3 & R\$ & $168,217.00$ \\
Yard 4 & R\$ & $35,297.00$ \\
Yard 5 & R\$ & $41,606.00$ \\
Yard 6 & R\$ & $39,960.00$ \\
Total & R\$ & $\mathbf{7 8 9 , 9 1 7 . 0 0}$ \\
\hline
\end{tabular}

On the other hand, the question of knowledge management [3] brings the aspects through which the organization drives and manages the generation, retention, sharing, strategic monitoring and application of information technology and knowledge in the corporate environment. In this context, the use of RFID provided a clearer view of the utilization rate of its fleet, subsidizing managers with precise numbers for decision making regarding the expansion and renewal of the fleet.

The need to reduce the idleness of vehicles emerged from the practical experience of the researchers and was the main motivator for the implementation of RFID technology in the case studied. The results achieved in this regard point to a successful project that reached the expectations outlined and exceeded the gains making new ways of using the tool were created, such as the TMS measurement (Average exit time) of the field teams Which began to be measured through RFID, by recording the exit times of the vehicles.

\section{Conclusions and Final Considerations}

Based on the results presented in the previous sections, the RFID technology used in fleet monitoring proved to be an effective and safe tool for controlling entry and exit of vehicles in Group X yards. In addition, it provided assistance to managers in decision making related to the acquisition of new vehicles, reduction of idle vehicles and reallocation between departments, which can bring financial gain to the company.

Despite the proven efficiency of RFID technology, Group X did not approve the expansion of this technology to all yards because of the high investment cost of deployment and maintenance, causing the P \& M team to continue to seek other tools to control $100 \%$ of the fleet.

This report can help companies in many industries think of a modern way of controlling their assets, because this technology allows monitoring not only vehicles but any type of object that the organization deems important and valuable, generating greater control, security, decreasing losses due to theft or misuse.

Among the future practical aspects, it is necessary to mention the possibilities of extending the perspective of idleness to a more general view of efficiency. 
Technologies that can provide better results in this sense are diverse, but the $\mathrm{P} \&$ $\mathrm{M}$ team has been dedicating itself to a new project that is based on the use of telemetry aiming at greater control of its fleet throughout the day, monitoring accelerations and sudden braking, excesses of speed, seeking to educate drivers to better preserve the company's assets and focus on the safety pillar, both of them and third parties.

In an improvement of the study, the visions of the user areas could be included, as well as a quantitative approach study to explore intervening aspects.

\section{References}

[1] Davenport, T.H. (2000) Ecologia da Informação. [Information Ecology.] 2nd Edition, Futura, São Paulo.

[2] Hessel, F., Rampim, R., Sacramento, V. and Bloch, S. (2009) Implementando RIFD na Cadeia de Negócios: Tecnologia a serviço da Excelência. [Implementing RIFD in the Business Chain: Technology at the Service of Excellence.] EdiPUCRS, Porto Alegre.

[3] Pessoa, C.R.M., Jamil, G.L., Gonçalves, D.M.R. and Souza, R.O. (2013) Gestão estratégica do conhecimento em produção: uso da tecnologia de Rfid (Radio-Frequency Identification) para controle de equipamentos ativos em ambientes industriais. [Management of Production Knowledge: Use of RFID Technology (Radio-Frequency Identification) for Control of Active Equipment in Industrial Environments.] Annals of the 10 th International Conference on Information Systems and Technology Management-CONTECSI, São Paulo, Brazil.

[4] Leite, C.E. and Silva, P.C.M. (2015) A utilização da tecnologia RFID na gestão do tráfego urbano. Anais do XI Congresso Nacional de Excelência em Gestão. [The Use of RFID Technology in the Management of Urban Traffic. Annals of the XI National Congress of Excellence in Management.] River of January, Brazil.

[5] Ahson, S.A. and Ilyas, M. (2008) RFID Handbook: Applications, Technology, Security, and Privacy. CRC Press, New York.

[6] Barbosa, R.E. and Taco, P.W.G. (2014) O uso da tecnologia de identificação de veículos por radiofrequência-RFID no planejamento de transportes. Anais do XXVIII Congresso de Pesquisa e Ensino em Transportes. [The Use of Technology to Identify Radiofrequency-RFID Vehicles in Transport Planning. Annals of XXVIII Congress of Research and Teaching in Transportation.] Curitiba, Brazil.

[7] Finkenzeller, K. (2010) RFID Handbook: Fundamentals and Applications in Contactless Smart Cards, Radio Frequency Identification and Near-Field Communication. 3rd Edition, John Wiley \& Sons, Ltd, Cambridge.

[8] Campos, F.C. and Belhot, R.V. (1994) Gestão de manutenção de frotas de veículos: uma revisão. [Management of Fleet Maintenance of Vehicles: A Review.] Management \& Production, 1, 171-188.

[9] Zeimpekis, V.S., Tarantilis, C.D., Giaglis, G.M. and Minis, I.E. (2007) Dynamic Fleet Management: Concepts, Systems, Algorithms \& Case Studies (v. 38). Springer Science \& Business Media, New York.

[10] Ichoua, S., Gendreau, M. and Potvin, J.Y. (2007) Planned Route Optimization for Real-Time Vehicle Routing. In: Zeimpekis, V.S., Tarantilis, C.D., Giaglis, G.M. and Minis, I. E., Eds., Dynamic Fleet Management: Concepts, Systems, Algorithms \& Case Studies (v. 38). Springer Science \& Business Media, New York, 1-18.

[11] Electric Power Distribution Company-Group X (2013a) Final Report of the Yard 
Monitoring Project. Report, João Pessoa.

[12] Electric Power Distribution Company-Group X (2013b) Presentation/System Utilization Training/PMF. Report, João Pessoa.

[13] Electric Power Distribution Company-Group X (2013c) Electronic Messages of Instruction and Evaluation of the System. Report, João Pessoa.

[14] Electric Power Distribution Company-Group X (2013d) Suggestion for Vehicle Optimization. Report, João Pessoa.

[15] Miles, M.B., Huberman, M. and Saldaña, J. (2014) Qualitative Data Analysis: A Methods Sourcebook. 3rd Edition, SAGE Publications, Inc., Thousand Oaks.

Submit or recommend next manuscript to OALib Journal and we will provide best service for you:

- Publication frequency: Monthly

- 9 subject areas of science, technology and medicine

- Fair and rigorous peer-review system

- Fast publication process

- Article promotion in various social networking sites (LinkedIn, Facebook, Twitter, etc.)

- Maximum dissemination of your research work

Submit Your Paper Online: Click Here to Submit

Or Contact service@oalib.com 